\title{
Tidally driven ice speed variation at Helheim Glacier, Greenland, observed with terrestrial radar interferometry
}

\author{
Denis VOYTENKO, ${ }^{1}$ Alon STERN, ${ }^{2}$ David M. HOLLAND, ${ }^{2}$ Timothy H. DIXON, ${ }^{1}$ \\ Knut CHRISTIANSON, ${ }^{2}$ Ryan T. WALKER ${ }^{3,4}$ \\ ${ }^{1}$ School of Geosciences, University of South Florida, Tampa, FL, USA \\ ${ }^{2}$ Courant Institute of Mathematical Sciences, New York University, New York, NY, USA \\ ${ }^{3}$ Cryospheric Sciences Laboratory, NASA Goddard Space Flight Center, Greenbelt, MD, USA \\ ${ }^{4}$ Earth System Science Interdisciplinary Center, University of Maryland, College Park, MD, USA \\ Correspondence: Denis Voytenko <dvoytenk@mail.usf.edu>
}

\begin{abstract}
We used a terrestrial radar interferometer (TRI) at Helheim Glacier, Greenland, in August 2013, to study the effects of tidal forcing on the terminal zone of this tidewater glacier. During our study period, the glacier velocity was up to $25 \mathrm{~m} \mathrm{~d}^{-1}$. Our measurements show that the glacier moves out of phase with the semi-diurnal tides and the densely packed melange in the fjord. Here detrended glacier displacement lags behind the forecasted tidal height by $\sim 8$ hours. The transition in phase lag between the glacier and the melange happens within a narrow $(\sim 500 \mathrm{~m})$ zone in the fjord in front of the ice cliff. The TRI data also suggest that the impact of tidal forcing decreases rapidly up-glacier of the terminus. A flowline model suggests this pattern of velocity perturbation is consistent with weak ice flowing over a weakly nonlinear bed.
\end{abstract}

KEYWORDS: glacier flow, glaciological instruments and methods, ice dynamics, ice/ocean interactions, remote sensing

\section{INTRODUCTION}

Tidal forcing of the speed of marine-terminating glaciers is an important aspect of ice/ocean interactions. Observing tidal forcing in a glacier's terminal region benefits from minute-scale, spatially dense measurements, which are now possible using terrestrial radar interferometry (TRI) (Rolstad and Norland, 2009; Dixon and others, 2012). Here we present new TRI measurements showing terminus-wide spatial and temporal impacts of tidal forcing, along with a model consistent with our observations at Helheim Glacier, a major marine-terminating outlet glacier on Greenland's southeast coast and one that is known to respond to tidal forcing (de Juan and others, 2010).

Helheim terminates into the 600-900 m deep Sermilik Fjord. The fjord is stratified, with upper cold polar water and deeper warm Atlantic water (Andresen and others, 2012; Straneo and others, 2012, 2013). The first $\sim 20 \mathrm{~km}$ adjacent to Helheim Glacier's terminus is usually packed with dense ice melange. Helheim Glacier accelerated and retreated between 2000 and 2005 (Howat and others, 2005; Rignot and Kanagaratnam, 2006) while, in aggregate, gaining mass between 2000 and 2010, likely due to an increase in accumulation (Howat and others, 2011). It is now considered to be Greenland's fifth largest glacier in terms of discharge (Enderlin and others, 2014).

Tidal signals have been observed in tidewater and floating-tongue glaciers throughout the world, with the tidal influence being present as far as $80 \mathrm{~km}$ up-glacier of the grounding line (Anandakrishnan and others, 2003). However, the effect of tides on ice motion is highly variable. Some glaciers, like the Ekström Ice Shelf, Antarctica (Heinert and Riedel, 2007), move in phase with the tides (i.e. high tide induces high velocity), while others, including Helheim Glacier, Greenland (de Juan and others, 2010), Jakobshavn Isbræ, Greenland (Podrasky and others, 2014), Columbia
Glacier, Alaska (Meier and Post, 1987; Walters and Dunlap, 1987), LeConte Glacier, Alaska (O'Neel and others, 2001), and the Brunt Ice Shelf, Antarctica (Doake and others, 2002), move out of phase with the tides (i.e. high tide induces low velocity).

Causes for out-of-phase motion have been summarized by Murray and others (2007) and include grounding-line back-stress reduction at low tide (Thomas, 2007), till properties that interact with changing water pressure to change resolved normal stress or effective friction at the glacier base (Gudmundsson, 2005), ocean currents that similarly change basal conditions (Doake and others, 2002), and variations in basal drag due to shifting of the grounding line (Heinert and Riedel, 2007; Sayag and Worster, 2013).

Recently, it has also been suggested that velocity at Helheim Glacier may be subject to diurnal variations caused by bed lubrication resulting from solar-driven surface melting (Davis and others, 2014), while calving may be strongly influenced by crevasse water depth and basal water pressure (Cook and others, 2014) and may happen in a buoyancy-driven manner (James and others, 2014).

\section{METHODS AND RESULTS}

We observed Helheim Glacier's terminal zone with a TRI (Fig. 1), collecting 5 days of radar observations (16-20 August 2013). Our TRI instrument is a GAMMA portable radar interferometer, a real-aperture radar that generates phase and amplitude images and makes line-of-sight (LOS) displacement measurements. The instrument operates at Kuband $(1.74 \mathrm{~cm}$ wavelength), and acquires images by rotational scanning (Werner and others, 2008). In normal operating conditions, the TRI has one transmitting and two receiving antennas, allowing generation of digital elevation 


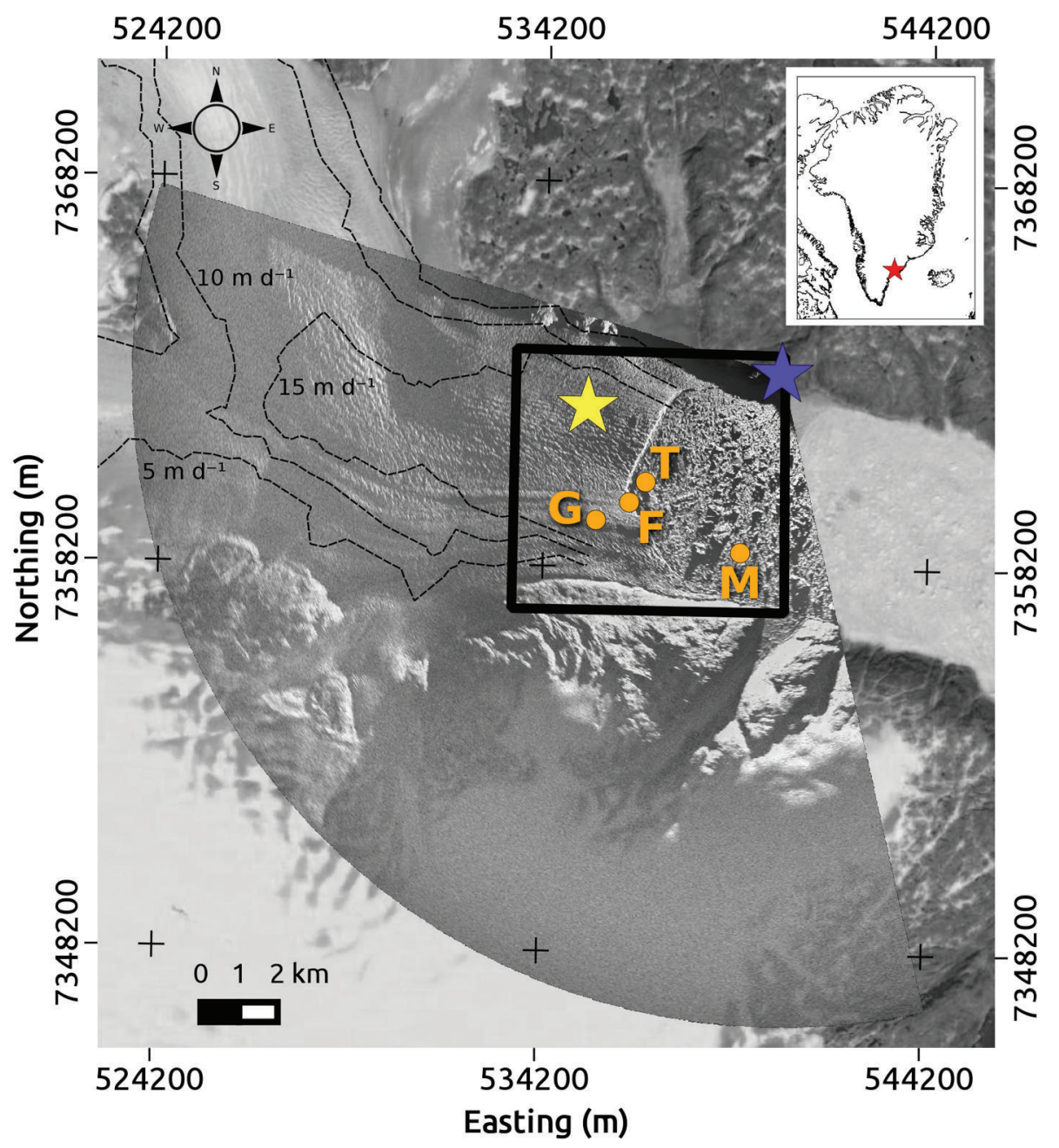

Fig. 1. (a) TRI radar amplitude image overlain on a Landsat image (27 July 2002; obtained from landsatlook.usgs.gov). The arc indicates the area scanned by the radar. The blue star represents the radar location, the black box outlines the area shown in Figures 2, 3 and 5, the orange dots $(\mathrm{G}, \mathrm{F}, \mathrm{T}$ and $\mathrm{M})$ show the locations of sampled points in Figure 4, and the yellow star represents the location of the GPS. Coordinates are in UTM zone $24 \mathrm{~N}$. Inset map shows location of Helheim Glacier (red star) along the southeast coast of Greenland. Dashed contours show interferometric synthetic aperture radar (InSAR)-derived velocities from 2008-09 MEaSUREs (Making Earth Science Data Records for Use in Research Experiments) Greenland ice sheet velocity map (Joughin and others, 2010a,b).

models (DEMs) of the imaged surface (Fig. 2). The instrument has a $0.75 \mathrm{~m}$ range resolution, and azimuth resolution that varies with distance. Our results are resampled to map coordinates with $10 \mathrm{~m}$ pixel spacing. Other characteristics of the instrument are summarized by Voytenko and others (2015).

The TRI was positioned above the fjord (300 ma.s.I.) $\sim 5 \mathrm{~km}$ away from the terminus (Fig. 1). The observations include 50 hours of continuous measurements with a single receiving antenna (the second antenna failed shortly after set-up), although we were able to obtain an initial DEM (Fig. 2). We scanned a $120^{\circ}$ arc covering the melange and the glacier surface every $2 \mathrm{~min}$. We also compared the TRI measurements with GPS measurements from a singlefrequency (L1) unit deployed on the glacier $\sim 2 \mathrm{~km}$ from the terminus (Fig. 1). No major calving events occurred during our study (see Supplementary information (http:// www.igsoc.org/hyperlink/14j173_supp.pdf)).

Our velocity analysis is based on interferometric measurements, i.e. the difference in backscattered phase from two consecutive observations. The unwrapped phase differences produce interferograms which show displacement over a given time period ( $2 \mathrm{~min}$ in this case). We averaged 2 hours of acquisitions to obtain a representative velocity map of the glacier surface and the proglacial melange (Fig. 3a). Integrating the displacement over time produces a displacement time series for each pixel in the radar image, the slope of which is the average LOS glacier velocity over that period.

The glacier has a mostly uniform average LOS motion up to $25 \mathrm{~m} \mathrm{~d}^{-1}$ (Fig. 3a), similar to the rate measured by de Juan and others (2010). Data from the GPS unit give a similar velocity to the TRI when converted to the radar LOS ( $22 \mathrm{~m} \mathrm{~d}^{-1}$ by TRI vs $23 \mathrm{~m} \mathrm{~d}^{-1}$ by the nearby GPS). A simple comparison of the terminus location in radar amplitude images from the beginning and end of the study also gives an average velocity of $\sim 25 \mathrm{~m} \mathrm{~d}^{-1}$. We estimate velocity uncertainty $\left( \pm 0.02 \mathrm{~m} \mathrm{~d}^{-1}\right)$ by measuring the displacement at motionless points (i.e. bare rock). It is also possible to estimate the glacier velocity in the direction of motion by assuming a negligible surface slope and dividing the measured LOS velocity at any pixel by the cosine of the angle given by the difference between the radar look direction to that point and the direction of ice motion $\left(95^{\circ}\right.$ clockwise from north in this case) (Fig. 3b) (Voytenko and others, 2015). 


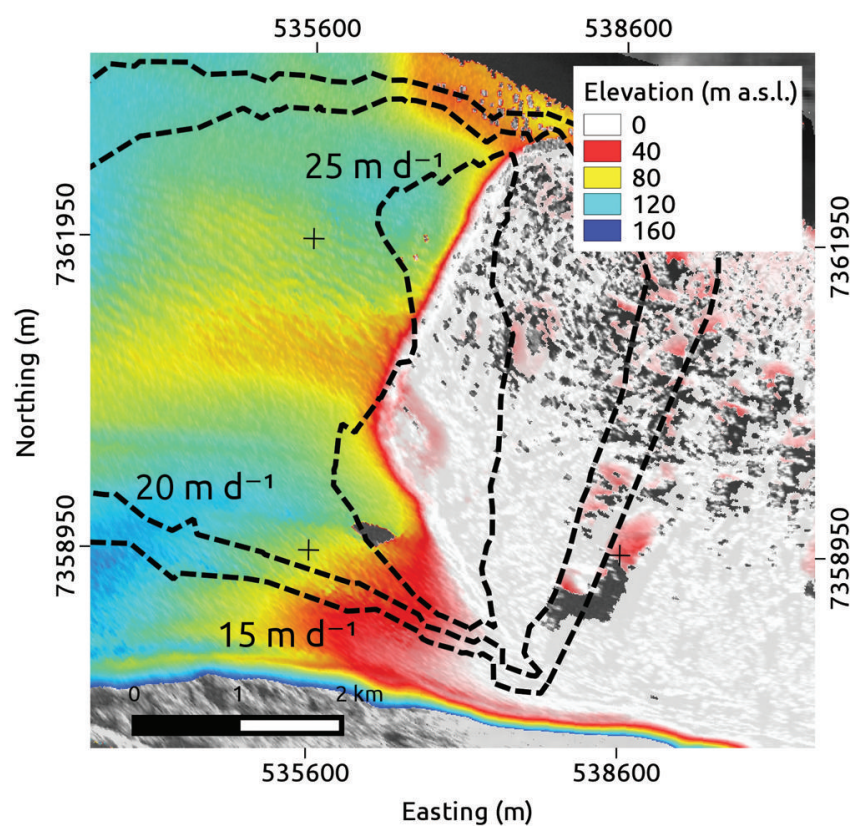

Fig. 2. TRI-derived DEM illustrating small variations in glacier topography near the terminus (elevations relative to local sea level). The contours represent velocities measured with the TRI adjusted for the direction of flow (Fig. 3b). There are higher velocities north and south of the lower-elevation medial moraine, outlining the trunks of the glacier.

Detrending the displacement time series allows us to observe small-scale variations in the glacier motion (Fig. 4). To generate the time series, we selected points where $90 \%$ of the time series was available (infilling the remaining 10\% with the average rate of motion). In all cases, the nondetrended time series show mostly linear motion (Fig. 4a), while the detrended time series show the influence of the semi-diurnal ( $\sim 12$ hour period) tide (Fig. 4b). Since our time series span only a few days, it is not possible to identify longer-period tidal components. Components $<12$ hours are not significant in the detrended time series.

In order to compare the velocity of the glacier and melange with the tidal amplitude in Sermilik Fjord, we used two approaches. First, we used forecasted tide data from Tasiilaq, $\sim 100 \mathrm{~km}$ away, available from the Danish Meteorological Institute (http://www.dmi.dk/en/groenland/hav/ tidevandstabeller-groenland/). We fitted a cubic spline to the forecasted high/low-tide data to generate a smooth tidal signal and used it as a proxy for the tidal signal in the fjord, comparing it with the detrended melange and ice motion signals (Fig. 4b). The predicted tides at Tasiilaq have a strong semi-diurnal signal, which appears in both the melange and glacier motion. The melange moves in phase with the tides $\left(\sim 0^{\circ}\right.$ phase angle, with small variations around large blocks of ice), while the glacier moves out of phase with a lag of $\sim 8$ hours, or $\sim 230^{\circ}$.

Second, we used the TRI data to estimate tides directly. Although the melange has significant vertical as well as horizontal motion, we can extract only one component from our LOS measurements. If we assume that the vertical component dominates, we can use the TRI data to compare melange motion to the forecasted tide from Tasiilaq, as follows. We take the displacement time series for a pixel in the melange whose horizontal motion (assumed down-fjord) is perpendicular to the radar LOS (i.e. we assume that the LOS measurement is little affected by horizontal motion and that there is no side-to-side motion in the fjord). Since the radar is positioned $\sim 300 \mathrm{~m}$ above the fjord, its near-range observations include a significant component of vertical motion of this pixel due to the vertical beamwidth of the antennas. Therefore, the radar measures a projection of the
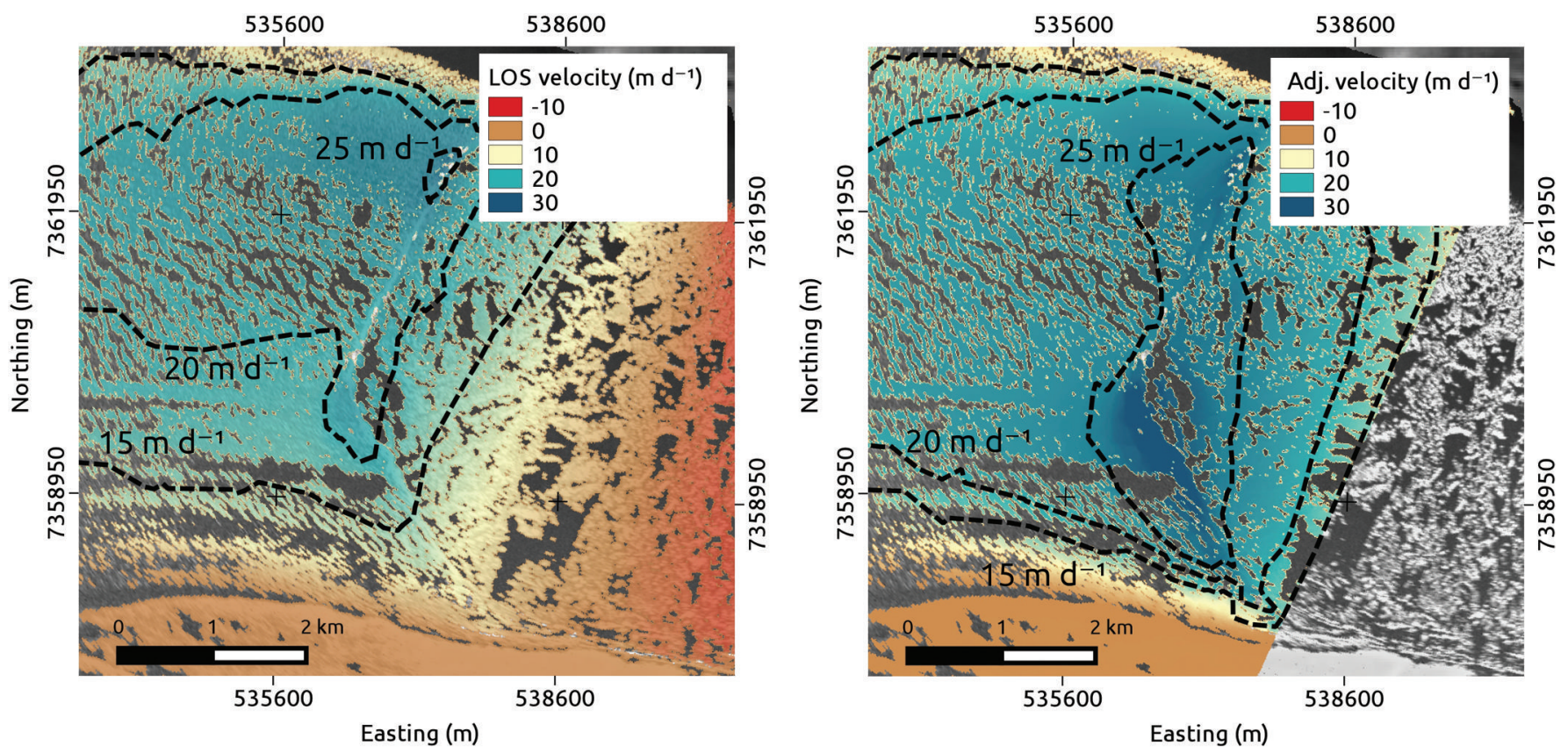

Fig. 3. Comparison between (a) measured LOS velocity and (b) velocity in the direction of glacier motion. The velocity in the direction of glacier motion was obtained by dividing the measured LOS velocity by the cosine of the angle given by the difference between the radar look direction to that point and the direction of ice motion $\left(95^{\circ}\right.$ clockwise from north). This suggests that it is possible to recover values close to the true magnitude of the glacier's velocity from the LOS measurements. Note that the area covered by the adjusted map is smaller than the area of the measured velocity. This is because this method does not work well in zones where the cosine of the angle between the radar look direction and the direction of ice motion approaches zero. 

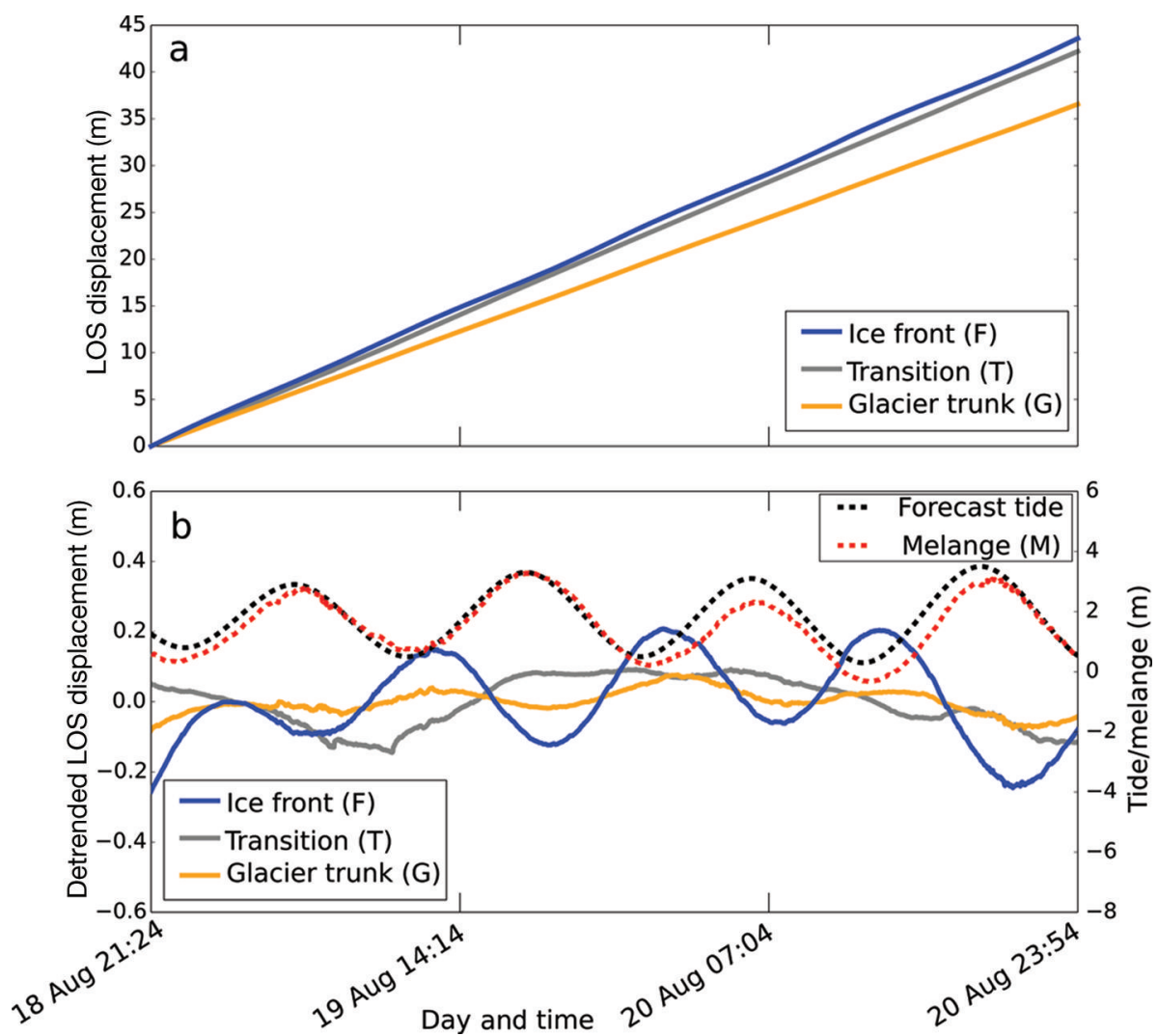

Fig. 4. Time series from August 2013. (a) Raw displacement time series for points on the glacier surface. (b) A comparison between the forecasted tides at Tasiilaq, melange motion measured directly by the TRI, and glacier motion. Note that even though the raw displacement time series appear to be almost linear, the precision of the TRI allows us to observe small-scale variations in the detrended data. The melange $(M)$ has a similar vertical range and moves in phase with the tides, while the glacier $(G, F)$ moves out of phase. The signal in the transition zone $(\mathrm{T})$ has weak tidal power and consequently lacks a characteristic sinusoid associated with a tidal signal. The motion of the glacier surface behind the terminus $(\mathrm{G})$ has a lower amplitude and an increased lag compared with the motion signal at the terminus (F). All acquisition times are UTC. The measurement uncertainty is $\sim 1 \mathrm{~mm}$ and the velocity uncertainty is $\sim 0.02 \mathrm{~m} \mathrm{~d}^{-1}$.

vertical motion of this pixel onto the look vector (LOS) (see Supplementary information (http://www.igsoc.org/ hyperlink/14j173_supp.pdf)). Subsequently, the full vertical motion can be estimated by dividing the measured motion by the ratio of radar elevation to slant range to the pixel. This projection closely matches the predicted tidal range (Fig. 4b).

During our observation period, high tide and high melange decrease the speed of the glacier by $\sim 10 \%$. We used spectral analysis to investigate the impact of tides on glacier and melange motion, specifically the spatial variability of a single tidal frequency (i.e. the dominant semidiurnal tide) in the detrended displacement time series. We decomposed each detrended displacement time series into its respective frequencies using a fast Fourier transform (FFT), and found the power of the frequency associated with the semi-diurnal tidal signal (12.6 hours from the FFT, close to the $\mathrm{M} 2$ and $\mathrm{N} 2$ tidal periods of 12.42 and 12.66 hours, respectively). A periodogram for each pixel shows the relationship between the spatial location and the power of the tidal frequency (proportional to the square of the tidal amplitude). This information was used to produce a map of tidal power (Fig. 5a) using the method of Glover and others (2011).

There is an apparent change in the power of the tidal frequency, with higher values close to the open fjord diminishing with proximity towards the terminus. This is a geometric artifact, reflecting the higher sensitivity of the instrument to vertical motion in the near field. With this geometry, the LOS sensitivity of the radar to vertical motion decreases with distance as a function of radar elevation divided by slant range. We corrected for this in the power map (Fig. 5a) and in Figure 6a by subtracting a theoretical sensitivity curve. After accounting for this effect, we observe a narrow zone ( $~ 500 \mathrm{~m}$ wide) of increased tidal power in the vicinity of the terminus (Fig. 6a).

We can also use the phase of the dominant frequency in the FFT to investigate changes in phase over the melange and ice front. We offset the phase to be 0 hours at the melange, and use it as a reference for the lag times. The phase is relatively constant within the melange up to the transition zone, where it begins to lag by $\sim 6$ hours $\left(170^{\circ}\right)$. The glacier ice experiences an additional lag of $\sim 30-60 \mathrm{~min}$ $\left(\sim 15-30^{\circ}\right)$ over the first $1 \mathrm{~km}$ from the ice front (Figs $5 \mathrm{~b}$ and 6b). A comparison profile between the tidal power and the phase lag is shown in Figure $6 b$, and examples of the detrended melange, transition zone and glacier motion signals are shown in Figure 4. The location of the transition zone is shown in Figure 5.

We model the glacier's velocity response to tidal forcing using the viscoelastic flowline model of Walker and others (2012, 2014), configured without an ice shelf. This model assumes negligible lateral drag from the glacier margins. Tidal forcing is considered a perturbation to a steady background velocity, defined by the momentum equation, which balances gravitational driving forces, related to ice density, ice thickness and basal topography, and resisting 

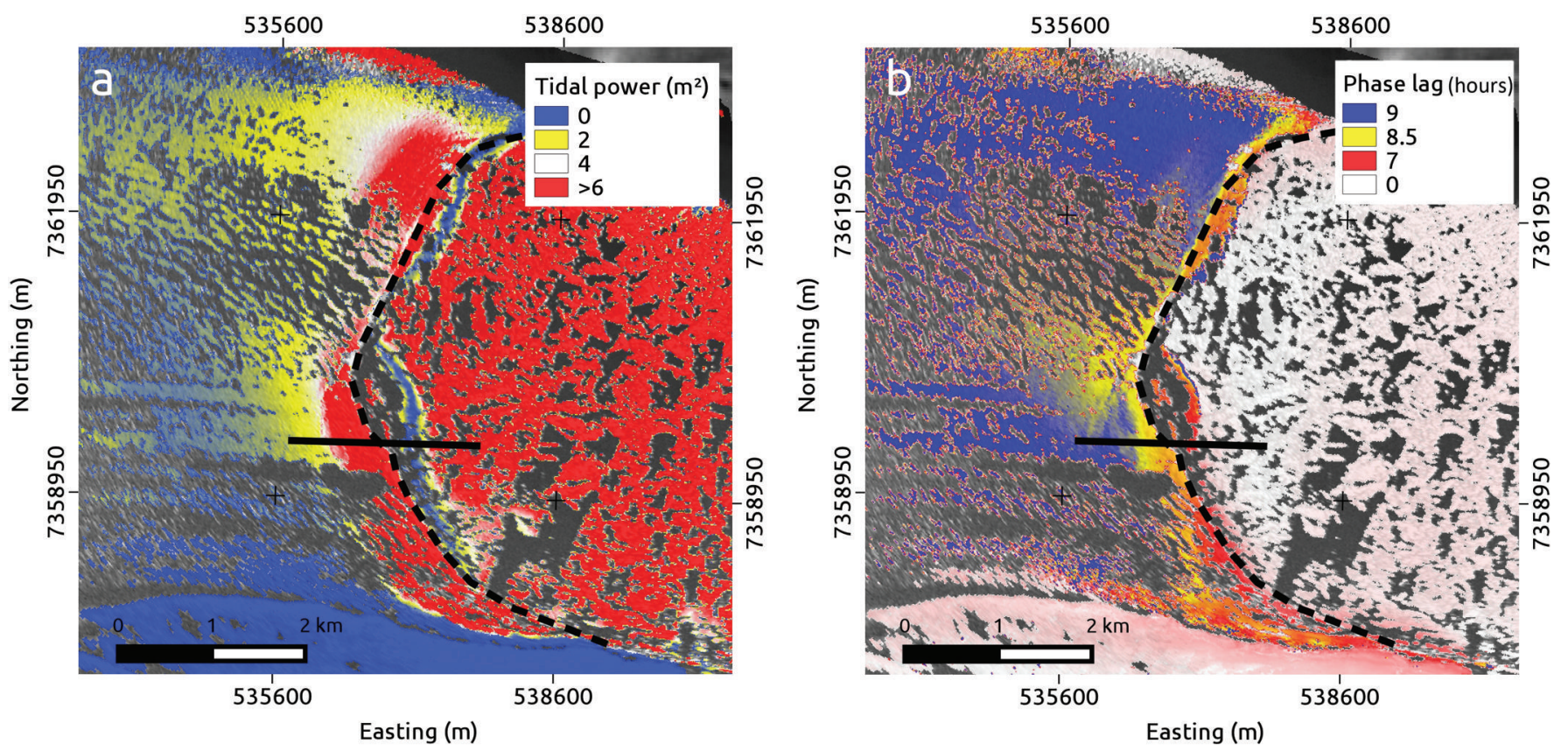

Fig. 5. (a) Spatial variability in corrected tidal power. Note that the tidal power is strong within the melange, and that it sharply drops off in front of the terminus, defining the transition zone. (b) Map of phase lag, with the melange lag set to 0 hours for reference. Note the sharp increase in phase lag at the transition zone at the terminus, followed by a gentle increase in phase lag up-glacier of the terminus. Also note that there is relatively sparse data coverage along the central trunk of the glacier due to heavy crevassing. The black line represents the profile in Figure 6 . The terminus outline is given by the dashed black curve.

forces from basal drag, $\tau_{\mathrm{b}}$, related to ice velocity, $u$, and shear stress exponent, $m$, for the glacier bed: $\tau_{\mathrm{b}}(u)=\beta^{2} u^{1 / m}$, where $\beta^{2}$ is an empirically determined coefficient fitted to velocity measurements. Ice rheology is represented by a simple Maxwell viscoelastic model, whereby ice responds elastically (defined by Young's modulus) on short timescales, and viscously on long timescales. For the short timescales considered here, the viscous term, ice thickness and bed topography can all be considered constant. At some upstream limit determined from observations, tidal perturbations can be considered negligible, leading to constant velocity and driving stress boundary conditions.

We focused on determining an optimal average Young's modulus, $E$, for the glacier ice and an average sliding law exponent, $m$, for the glacier bed over the first $10 \mathrm{~km}$ upglacier of the terminus (the area imaged by the TRI that is sensitive to tidal forcing). The boundary conditions of the model include a periodic stress rate at the ice front, implying that the only stress causing the velocity perturbation is the hydrostatic pressure change from the tide forced solely by the M2 tidal component. The model also assumes a constant ice thickness of $700 \mathrm{~m}$ (which also represents flat bed topography, as the model depends on ice thickness rather than directly on the bed) and an ice viscosity of $10^{14} \mathrm{Pas}$. Following de Juan (2011), we assigned a background basal shear stress of $170 \mathrm{kPa}$, and set the upstream distance parameter and upstream velocity at which the tidal forcing becomes negligible to $12-16 \mathrm{~km}$ and $10 \mathrm{~m} \mathrm{~d}^{-1}$, respectively. In order to increase the signal-to-noise ratio for input data to the model, we used a synthetic inline velocity time series derived from the tidal data and the TRI measurements by filtering the data for the dominant $\mathrm{M} 2$ tidal constituent using T-TIDE (Pawlowicz and others, 2002), a MATLAB ${ }^{\circledR}$-based toolkit for analyzing the harmonic properties of ocean tides.
We tested $E$ values between $0.1 \mathrm{GPa}$ (weak ice) and $1 \mathrm{GPa}$ (stronger ice) and varied the sliding law exponent between 1 (linear bed), 3 (weakly nonlinear bed) and 8 (nonlinear bed).

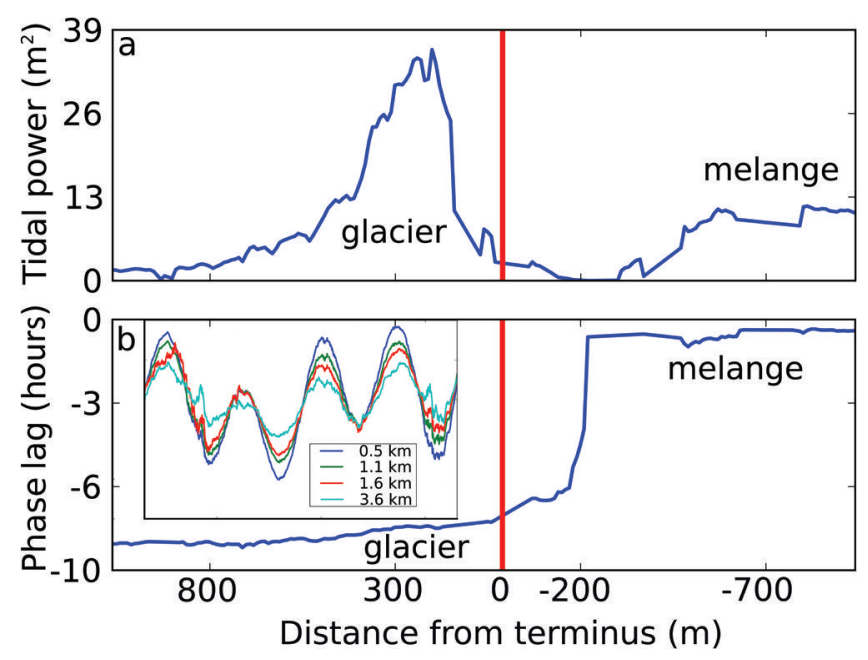

Fig. 6. A smoothed transect along the flow direction of the glacier showing variability in (a) tidal power and (b) phase lag. The power is the sum of the squares of the real and imaginary components of the dominant FFT signal; the phase is the inverse tangent ratio. The terminus location is marked by the vertical red line. Note the relatively sharp spike (i.e. drop-off and pick-up) in the tidal power around the terminus, and the corresponding rapid change in phase. The inset in (b) shows the typical detrended signal in glacier motion (displacement vs time) with increasing distance from the terminus (distances given in legend). Increasing up-glacier distance from the terminus reduces tidal amplitude and slightly increases the phase lag, which is visible in the inset above the legend. This phase lag corresponds with the sloping portion of the main part of the figure directly below the inset. The full vertical range in the inset is $\sim 20 \mathrm{~cm}$, while the horizontal axis spans $\sim 2$ days. 


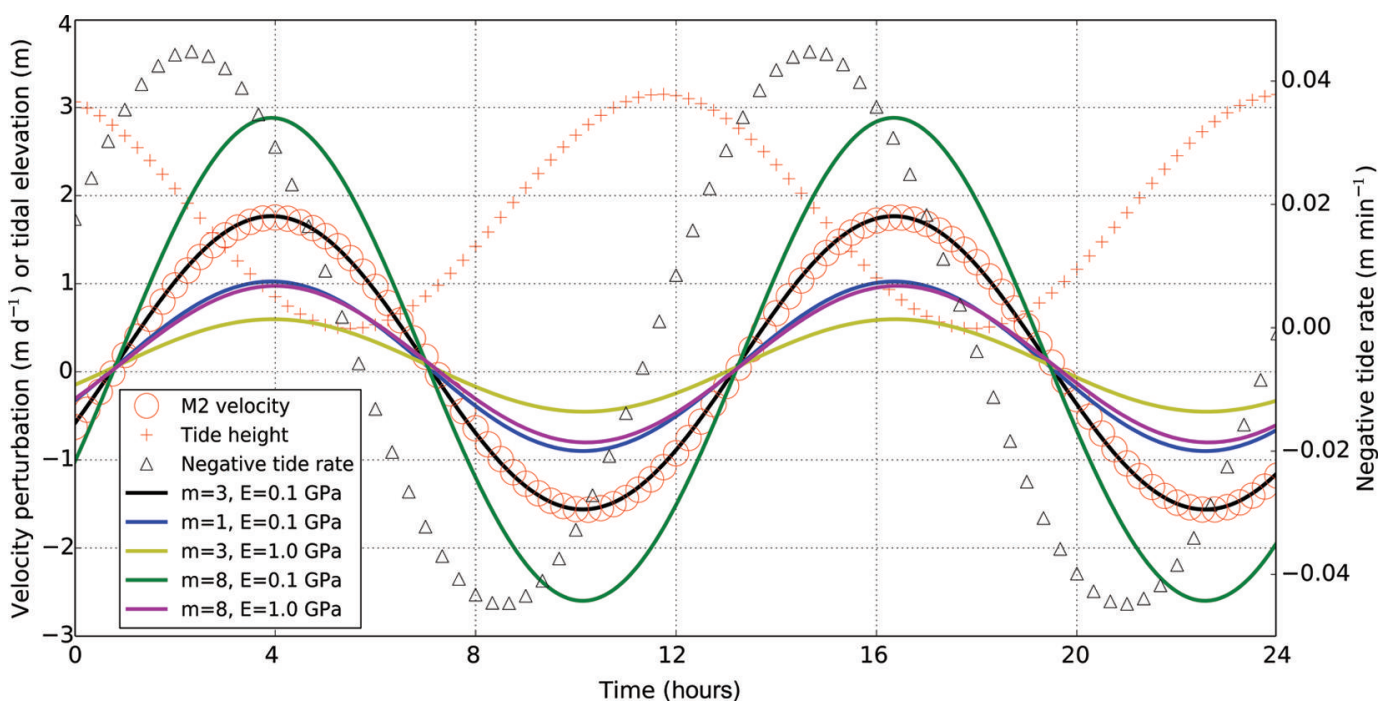

Fig. 7. Model results and comparison with tidal height, negative applied tidal rate and velocity perturbation. The best-fit model (black curve) with $E=0.1 \mathrm{GPa}$ (weak ice) and $m=3$ (weakly nonlinear bed) closely matches the velocity response of the terminus to tidal perturbations (red circles, M2 velocity component). When $E=1 \mathrm{GPa}$ and $m=3$ (yellow curve) there is little response at the terminus and too much upstream. When $m=1$ and $E=0.1 \mathrm{GPa}$ (blue curve) there is an inadequate response at the terminus, suggesting that $E$ needs to be lowered even more to match the terminus value. However, this might not be physically plausible. When $m=8$ and $E=0.1 \mathrm{GPa}$ (green curve), the velocity response at the terminus is too high, while increasing $E$ to $1 \mathrm{GPa}$ (magenta curve) reduces the terminus response too much and causes a greater response upstream. Note that the plotted velocity perturbation (M2 velocity) appears smoothed because it is a single tidal frequency representation of the data from the TRI measurements.

The best-fit model for the glacier's response to tidal forcing suggests weak ice $(E=0.1 \mathrm{GPa})$ flowing over a linear or weakly nonlinear bed ( $m=3)$ (Fig. 7).

\section{DISCUSSION}

While the majority of glacier speed variation we observe is associated with a 12 hour tidal period, the melange and glacier motion are out of phase (Fig. 6). This transition happens in the fjord in front of the terminus. In this zone, the melange, which is in phase with the tides far from the glacier, transitions to an out-of-phase signal synchronized with the glacier motion. Figure 4 shows the comparison of the glacier/melange motion with the tides, and illustrates the presence of the transition zone and the existence of phase lags on the glacier surface, which increase with distance from the terminus. There is no apparent transition zone in the melange between the deeper portion of the fjord and the fjord walls (Fig. 5), suggesting that the melange near the walls is reasonably loose and is directly influenced by the tides. However, a broader radar coverage of both fjord walls (currently only the south wall is visible in the radar imagery) would be necessary to confirm this.

We hypothesize that the transition from in-phase melange motion to out-of-phase glacier motion, and the narrowness of the transition zone, can be explained as follows. The fjord is dominated by the tightly packed melange, which moves in phase with the tidal signal, and has a relatively constant tidal power up to $\sim 1 \mathrm{~km}$ from the glacier terminus. The drop in tidal power before the sharp increase corresponds to the location in the melange that is starting to feel the frictional resistance of the ice wall (damping vertical motions of the melange), and where the signal starts to change to an out-of-phase signal like that of the glacier (i.e. the phase change happens in the fjord). Destructive interference nearly eliminates the tidal signal in a band near the calving front (Fig. 5). Approximately $300 \mathrm{~m}$ from the terminus (still in the melange) the tidal signal picks up again, but this time, out of phase with the tides (high tide - low velocity), reaching a local power maximum around the ice cliff. Subsequently, the power of the tidal frequency begins to diminish with distance inland from the terminus.

The melange/glacier profile shows a small phase lag with increasing up-glacier distance from the calving front (30$60 \mathrm{~min}$ over the first kilometer, in addition to the phase lag difference between the terminus and the melange) (Fig. 6). The phase lag may reflect glacier bed rheology, as friction from sliding over the bed sediments may dampen and offset the glacier's response to tides (Walker and others, 2014). In the first kilometer up-glacier from the calving front, the amplitude of the detrended displacement is damped by a factor of three $(0.15 \mathrm{~m}$ amplitude at the ice front vs $0.05 \mathrm{~m}$ amplitude behind the ice front) with a small change in phase lag (Figs 4 and 6). The glacier's response to tides is also highly dependent on the rate of applied stress, which is controlled by the tidal period. A semi-diurnal tide has higher applied stress rates than a diurnal tide, suggesting that a semi-diurnal tide can cause the same velocity perturbation as a diurnal tide but with only half the tidal amplitude (Walker and others, 2014).

The two key variables in the flowline model are Young's modulus, $E$, reflecting the elastic properties of ice, and the sliding law exponent, $m$, reflecting bed rheology. The modeling goal was to get $E$ low enough and $m$ high enough that the modeled signal matched the measured velocity perturbation at the terminus, without propagating tidal effects too far upstream. High $E$ makes the ice stiffer and harder to deform for a given forcing, and causes deformation to extend further upstream. Low $E$ has the opposite effect, and looks more like our data, resulting in a reasonably large response relative to the size of the forcing with a lack of upstream propagation. High $m$ (i.e. plastic bed) leads to a large response to forcing that propagates upstream strongly and rapidly. Plasticity (infinitely high $\mathrm{m}$ ) 
also causes the glacier to respond instantaneously to the tide rate, which is not observed in the data. In the best-fit model with weak ice $(E=0.1 \mathrm{GPa})$ flowing over a linear or weakly nonlinear bed $(m=3)$, the lag between the glacier's velocity response and the applied tidal rate is $\sim 1.5$ hours, or $\sim 45^{\circ}$, for the semi-diurnal tide, matching the observations shown in Figure 7.

The low value of Young's modulus $(E=0.1 \mathrm{GPa})$ compared with laboratory results for unfractured ice $(E=9.3 \mathrm{GPa})$ (Reeh and others, 2003) probably reflects the deeply crevassed and damaged ice in the first $\sim 10 \mathrm{~km}$ upstream of the terminus. Furthermore, the modeled area also happens to be the zone where trunks of the glacier merge and bend, which may influence the ice behavior due to additional compression. The weakly nonlinear bed parameter likely suggests that the glacier motion may be controlled by ice deformation, sliding over a hard bed or low-stress-exponent till deformation, as opposed to sliding over weakly velocity-strengthening till arising from a plastic bed (Licciardi and others, 1998; Walker and others, 2012).

Although we did not observe any calving events, the modeling from this study can be used as a starting point for more detailed modeling efforts (e.g. those that include a two-dimensional map plane version of the flowline model, calving and additional TRI measurements). It is also important to note that our current model focuses only on the first $10 \mathrm{~km}$ upstream of the terminus, assumes uniform and time-invariant bed properties, and does not address any changes in the surface slope of the glacier with time. Changing the ice thickness (also a proxy for bed topography) changes only the amplitude of the tidal signal (but not its timing), with negligible effects considering that the ice is very weak. Furthermore, the upstream distance and velocity, where the tidal forcing becomes negligible were determined from an older dataset (de Juan, 2011), suggesting that concurrent TRI measurements near the terminus and GPS measurements further upstream may be valuable for future studies. Targeted radio-echo sounding is also needed to account for the variable bed topography and the possibility of temperate ice at depth, which would result in a depthdependent ice rheology, not considered in our model.

\section{CONCLUSIONS}

We have presented a new method for observing the relationship between tides, proglacial melange and glacier velocity. At Helheim Glacier, the melange/glacier motion relationship suggests that tidal forcing has a direct impact on glacier velocity. High tide resists and slows the glacier, while low tide allows the glacier to speed up. During our study period, the glacier velocity was up to $25 \mathrm{~m} \mathrm{~d}^{-1}$ and detrended glacier displacement was $\sim 8$ hours out of phase with the tidal height. Modeling suggests that the magnitude and timing of the glacier's velocity response to tidal forcing represents weak ice flowing over a weakly nonlinear bed, suggesting that the motion may be controlled by ice deformation, sliding over a hard bed or low-stress-exponent till deformation. The dense spatial and temporal coverage of the glacier provided by TRI allowed us to produce spatial maps of the tidal response and lag, where previously this has only been done on a streamline. The TRI also allowed us to describe the variability in the phase lag between the melange and the glacier, in particular, imaging a narrow ( $\sim 500 \mathrm{~m}$ wide) transition zone in front of the terminus.

\section{ACKNOWLEDGEMENTS}

Field support for this project was provided by NYU Abu Dhabi grant G1204 and US National Science Foundation (NSF) Office of Polar Programs grant ARC-0806393. Analysis was supported in part by NASA grant NNX12AB69G to D.M.H. and NNX12AK29G to T.H.D. Denise Holland is thanked for organizing the field logistics and project meetings. Additional support to D.V. and T.H.D. was provided by start-up funds from the University of South Florida. We thank Martin Truffer, Ted Scambos and an anonymous reviewer, along with two anonymous reviewers of an earlier version of the manuscript, for their valuable comments.

\section{REFERENCES}

Anandakrishnan S, Voigt DE, Alley RB and King MA (2003) Ice stream $D$ flow speed is strongly modulated by the tide beneath the Ross Ice Shelf. Geophys. Res. Lett., 30(7), 1361 (doi: 10.1029/2002GL016329)

Andresen CS and 8 others (2012) Rapid response of Helheim Glacier in Greenland to climate variability over the past century. Nature Geosci., 5(1), 37-41 (doi: 10.1038/ngeo1349)

Cook S and 7 others (2014) Modelling environmental influences on calving at Helheim Glacier in eastern Greenland. Cryosphere, 8(3), 827-841 (doi: 10.5194/tc-8-827-2014)

Davis JL, de Juan J, Nettles M, Elosegui P and Andersen ML (2014) Evidence for non-tidal diurnal velocity variations of Helheim Glacier, East Greenland. J. Glaciol., 60(224), 1169-1180 (doi: $10.3189 / 2014$ JoG13J230)

De Juan J (2011) Tidewater glacier flow of Helheim Glacier, Greenland, 2006-2008, using high-rate GPS. PhD thesis, Universitat de Barcelona

De Juan J and 9 others (2010) Sudden increase in tidal response linked to calving and acceleration at a large Greenland outlet glacier. Geophys. Res. Lett., 37(12), L12501 (doi: 10.1029/ 2010GL043289)

Dixon TH and 8 others (2012) Emerging technology monitors icesea interface at outlet glaciers. Eos, 93(48), 497-498 (doi: 10.1029/2012EO480001)

Doake CSM and 6 others (2002) Tide-induced lateral movement of Brunt Ice Shelf, Antarctica. Geophys. Res. Lett., 29(8), 1226 (doi: 10.1029/2001GL014606)

Enderlin EM, Howat IM, Jeong S, Noh M, Angelen JH and Van den Broeke MR (2014) An improved mass budget for the Greenland ice sheet. Geophys. Res. Lett., 41(3), 866-872 (doi: 10.1002/ 2013GL059010)

Glover DM, Jenkins WJ and Doney SC (2011) Modeling methods for marine science. Cambridge University Press, Cambridge

Gudmundsson GH (2005) Long-range tidal effects on Rutford Ice Stream, Antarctica. Geophys. Res. Abstr., 7, EGU05-A-01624

Heinert M and Riedel B (2007) Parametric modelling of the geometrical ice-ocean interaction in the Ekströmisen grounding zone based on short time-series. Geophys. J. Int., 169(2), 407-420 (doi: 10.1111/j.1365-246X.2007.03364.x)

Howat IM, Joughin I, Tulaczyk S and Gogineni S (2005) Rapid retreat and acceleration of Helheim Glacier, east Greenland. Geophys. Res. Lett., 32(22), L22502 (doi: 10.1029/ 2005GL024737)

Howat IM, Ahn Y, Joughin I, Van den Broeke MR, Lenaerts J and Smith B (2011) Mass balance of Greenland's three largest outlet glaciers, 2000-2010. Geophys. Res. Lett., 38(12), L12501 (doi: 10.1029/2011GL047565)

James TD, Murray T, Selmes N, Scharrer K and O'Leary M (2014) Buoyant flexure and basal crevassing in dynamic mass loss at Helheim Glacier. Nature Geosci., 7(8), 593-596 (doi: 10.1038/ ngeo2204) 
Joughin I, Smith BE, Howat IM and Scambos T (2010a) MEaSUREs Greenland Ice Sheet Velocity Map from InSAR Data. National Snow and Ice Data Center Distributed Active Archive Center, Boulder, CO http://dx.doi.org/10.5067/MEASURES/ CRYOSPHERE/nsdic-0478.001

Joughin I, Smith BE, Howat IM, Scambos $T$ and Moon $T$ (2010b) Greenland flow variability from ice-sheet-wide velocity mapping. J. Glaciol., 56(197), 415-430 (doi: 10.3189/ 002214310792447734)

Licciardi JM, Clark PU, Jenson JW and MacAyeal DR (1998) Deglaciation of a soft-bedded Laurentide Ice Sheet. Quat. Sci. Rev., 17(4-5), 427-448 (doi: 10.1016/S0277-3791(97)00044-9)

Meier MF and Post A (1987) Fast tidewater glaciers. J. Geophys. Res., 92(B9), 9051-9058 (doi: 10.1029/JB092iB09p09051)

Murray T, Smith AM, King MA and Weedon GP (2007) Ice flow modulated by tides at up to annual periods at Rutford Ice Stream, West Antarctica, Geophys. Res. Lett., 34(18), L18503 (doi: 10.1029/2007GL031207)

O'Neel S, Echelmeyer KA and Motyka RJ (2001) Short-term flow dynamics of a retreating tidewater glacier: LeConte Glacier, Alaska, USA. J. Glaciol., 47(159), 567-578

Pawlowicz R, Beardsley B and Lentz S (2002) Classical tidal harmonic analysis including error estimates in MATLAB using T_TIDE. Comput. Geosci., 28(8), 929-937 (doi: 10.1016/S00983004(02)00013-4)

Podrasky D, Truffer M, Lüthi ML and Fahnestock M (2014) Quantifying velocity response to ocean tides and calving near the terminus of Jakobshavn Isbræ, Greenland. J. Glaciol., 60 (222), 609-621 (doi: 10.3189/2014JoG13J130)

Reeh N, Christensen EL, Mayer C and Olesen OB (2003) Tidal bending of glaciers: a linear viscoelastic approach. Ann. Glaciol., 37(1), 83-89 (doi: 10.3189/172756403781815663)

Rignot E and Kanagaratnam P (2006) Changes in the velocity structure of the Greenland Ice Sheet. Science, 311(5763), 986-990 (doi: 10.1126/science.1121381)

Rolstad C and Norland R (2009) Ground-based interferometric radar for velocity and calving-rate measurements of the tidewater glacier at Kronebreen, Svalbard. Ann. Glaciol., 50(50), 47-54 (doi: 10.3189/172756409787769771)

Sayag R and Worster MG (2013) Elastic dynamics and tidal migration of grounding lines modify subglacial lubrication and melting. Geophys. Res. Lett., 40(22), 5877-5881 (doi: 10.1002/ 2013GL057942)

Straneo F and 8 others (2012) Characteristics of ocean waters reaching Greenland's glaciers. Ann. Glaciol., 53(60), 202-210 (doi: 10.3189/2012AoG60A059)

Straneo F and 9 others (2013) Challenges to understanding the dynamic response of Greenland's marine terminating glaciers to oceanic and atmospheric forcing. Bull. Am. Meteorol. Soc., 94 1131-1144 (doi: 10.1175/BAMS-D-12-00100.1)

Thomas RH (2007) Tide-induced perturbations of glacier velocities. Global Planet. Change, 59(1), 217-224 (doi: 10.1016/j.gloplacha.2006.11.017)

Voytenko D and 7 others (2015) Multi-year observations of Breiðamerkurjökull, a marine-terminating glacier in southeastern Iceland, using Terrestrial Radar Interferometry. J. Glaciol., 61(225), 42-54 (doi: 10.3189/2015JoG14J099)

Walker RT Christianson K, Parizek BP, Anandakrishnan S and Alley RB (2012) A viscoelastic flowline model applied to tidal forcing of Bindschadler Ice Stream, West Antarctica. Earth Planet. Sci. Lett., 319, 128-132 (doi: 10.1016/j.epsl.2011.12.019)

Walker RT, Parizek BR, Alley AB, Brunt KM and Anandakrishnan S (2014) Ice-shelf flexure and tidal forcing of Bindschadler Ice Stream, West Antarctica. Earth Planet. Sci. Lett., 395, 184-193 (doi: 10.1016/j.epsl.2014.03.049)

Walters RA and Dunlap WW (1987) Analysis of time series of glacier speed: Columbia Glacier, Alaska. J. Geophys. Res., 92(B9), 8969-8975 (doi: 10.1029/JB092iB09p08969)

Werner C, Strozzi T, Wiesmann A and Wegmüller U (2008) GAMMA's portable radar interferometer. In Chrzanowski $\mathrm{A}$ Rizos C, Henriques MJ and Whitaker C eds Proceedings of the 13th FIG Symposium on Deformation Measurements and analysis, May 2008, LNEC, Lisbon, Vol. 12. International Federation of Surveyors, Copenhagen, 16 